\title{
CERITA RAKYAT DI KABUPATEN KUNINGAN SEBAGAI RUJUKAN BAHAN AJAR MATA PELAJARAN BAHASA SUNDA ; KAJIAN FOKLOR
}

\author{
Asep Jejen Jaelani \\ Universitas Kuningan \\ gilang.krispiyadi@yahoo.co.id
}

\begin{abstract}
From the results of sample data analysis, both literature and respondent figures were found 19 (nineteen) collections of folktales. The existing genre from the nineteen collections of folklore includes: 1) six genres of sasakala (legend), 2) four genres of dongéng sasatoan (fables), 3) two genre of myth (mythical stories), 4) three genres of human life (farabel ), and 5) four genre chronicles (stories of the origin of place events). Of the 19 (nineteen) folklore data, 7 (seven) of them are folklore that has been spread from generation to generation in the Sundanese community of Kuningan Regency, while 12 other folklore stories are folktales from the Sundanese people of West Java and Banten spread in Kuningan communities. From the translation of morality values found, namely: (1) human morality to God (MMT), which amounted to 3 (three) folklore (15\%), entitled "Nyi Anteh, Tukang Kai, jeung Syekh Abdul Qodir Jaélani"; (2) human morality towards him (MMD), totaling 2 stories (10.5\%), entitled "Ciung Wanara and Sangkuriang"; (3) human morality (MMM), totaling 11 folklore (57.8\%), entitled "Dako Dewah, Syeh Abdul Qodir Jaélani, Sasakala Cigugur, Sasakala Batu Ceurik, Hawangan Surakatiga, Sakdang Kuya jeung Ngalanangka Monkey, Oray cai Teu Peurahan, Sireum jeung Gajah, Nyi antéh, Ciung Wanara, and Maung Panjalu "; and (4) Human moral nature (MMA), totaling 5 (five) collections of folktales (26\%), entitled "Hayam Pelung, Sasakala Cigugur, Hawangan Surakatiga, Jalaksana Sasakala, Sakadang Kuja Jeung Maung Silih Duruk". while (5) Human morality over time (MMW) there are 3 (three) folklore stories (15\%), entitled "Sangkuriang, Si Kabayan in Cukur, and Sakadang Kuya jeung Maung silih Duruk"
\end{abstract}

Keywords: Folklore, Morality, Teaching Materials

\begin{abstract}
Abstrak
Dari hasil analisis sample data, baik bersumber pustaka maupun responden tokoh ditemukan 19 (Sembilan belas) kumpulan cerita rakyat. Genre yang ada dari ke-sembilanbelas kumpulan cerita rakyat tersebut meliputi: 1) enam genre sasakala (legenda), 2) empat genre dongéng sasatoan (fabel), 3) dua bergenre mite (cerita mitos), 4) tiga genre kehidupan manusia (farabel), dan 5) empat bergenre babad (cerita asal muasal kejadian tempat). Dari 19 (sembilan belas) data cerita rakyat, 7 (tujuh) diantaranya cerita rakyat has yang tersebar turun temurun di masyarakat Sunda Kabupaten Kuningan, sedangkan 12 kumpulan cerita rakyat lainnya merupakan cerita rakyat masyarakat Sunda Jawa Barat dan Banten yang tersebar di masyarakat Kuningan. Dari penjabaran nilai moralitas yang ditemukan yaitu: (1) moral manusia kepada tuhan (MMT), yang berjumlah 3 (tiga) cerita rakyat (15\%), berjudul "Nyi Anteh, Tukang Kai, jeung Syekh Abdul Qodir Jaélani"; (2) moral manusia terhadap dirinya (MMD), berjumlah 2 cerita ( 10,5 \%), berjudul "Ciung Wanara dan Sangkuriang"; (3) moral manusia terhadap manusia (MMM), berjumlah 11 cerita rakyat ( 57,8 \%), berjudul "Embah Dako, Syeh Abdul Qodir Jaélani, Sasakala Cigugur, Sasakala Batu Ceurik, Hawangan Surakatiga, Sakdang Kuya jeung Monyet Ngalanangka, Oray cai Teu Peurahan, Sireum jeung Gajah, Nyi antéh, Ciung Wanara, dan Maung Panjalu"; dan (4) Moral manusia terhadap alam (MMA), berjumlah 5 (lima) kumpulan cerita rakyat (26\%), berjudul "Hayam Pelung, Sasakala Cigugur, Hawangan Surakatiga, Sasakala Jalaksana, Sakadang Kuja Jeung Maung Silih Duruk ”. sedangkan (5) Moral manusia terhadap waktu (MMW) ada 3 (tiga) cerit rakyatr (15\%), berjudul "Sangkuriang, Si Kabayan di Cukur, dan Sakadang Kuya jeung Maung silih Duruk"
\end{abstract}

Kata Kunci: Cerita Rakyat, Moralitas, Bahan Ajar 


\section{PENDAHULUAN}

\section{Latar Belakang Masalah Penelitian}

Fungsi budaya dalam kegiatan interaksi sosial masyarakat, tentunya memiliki peranan yang sangat penting, karena budaya merupakan fungsi alat control sosial, oleh kareena itu budaya bisa memberikan kontrol terhadap norma-norma manusia. Untuk membentengi sifat negatif dalam interaksi sosial masyarakat, perlu system tradisi budaya yang bisa membentengi dari hal-hal yang diluar norma/ adat. Sedangkan warisan budaya adalah benda atau atribut tak berbenda yang merupakan jati diri suatu masyarakat atau kaum yang diwariskan dari generasi-generasi sebelumnya, yang dilestarikan untuk generasi-generasi yang akan datang. Warisan budaya dapat berupa benda, seperti monumen, artefak, dan kawasan, atau tak benda, seperti tradisi, bahasa, dan ritual. Dalam kehidupan bermasyarakat Nusantara Indonesia ada trust dan warisan kuno tak berbeda, dan menyebar secara lisan namun tidak diketahui siapa penciptanya salahsatunya cerita rakyat atau dongeng.

\section{Metode Penelitian}

Metode yang akan digunakan yaitu métode deskriptif analitik. Dalam metode déskriptif analitik ini, akan mendeskripsikan dan menganalisis struktur dari kumpulan cerita-cerita rakyat yang tersebar di beberapa wilayah Kabupaten Kuningan. Diharapkan dengan metode ini, objek bisa dimaknai secara maksimal (Ratna, 2010, hlm. 334). dalam Arikunto (2010, hlm. 3) menjelaskan bahwa metode deskriptif merupakan metode yang digunakan untuk menliti keadaan, kondisi, situasi, kejadian, kegiatan, yang hasilnya disusun dalam bentuk laporan. Dalam Suyatna (2002, hlm. 14), menjelaskan bahwa metode penelitian deskriptif merupakan metode penelitian yang bersifat campuran data dasar, bersifat deskriptif, satu hipotésis, tidak membuat ramalan atau tidak mencari makna implikasi. Yang menjadi dasar menggunakan metode déskriptif analitik untuk mendalami makna dan mendeskripsikan nilai moralitas étnopedagogik yang terkandung dalam kumpulan cerita di masyarakat Sunda di Kabupaten Kuningan, sebagai rujukan bahan ajar.

\section{HASIL DAN PEMBAHASAN}

Dalam bab ini akan dibahas dua hal yang berkaitan dengan fokus objek kumpulan cerita rakyat masyarakat Sunda di Kabupatén Kuningan, diantaranya: (1) Deskripsi-deskripsi kumpulan cerita rakyat masyarakat Sunda di Kabupatén Kuningan; (2) Nilai moralitas (etnopedagogik) yang terkandung dari setiap cerita rakyat Masyarakat Kabupaten Kuningan sebagai rujukan bahan ajar. Berdasarkan data di lapangan, kumpulan cerita rakyat masarakat Sunda sacara umum dan khususnya yang tersebar di Kabupaten Kuningan, kumpulan cerita rakyat yang terhimpun ada beberapa genre, seperti; 1) babad atau cerita asal muasal tempat, 2) dongéng sasatoan/fable, 3) farabel, 4) mite dan 5) sasakala/ Legenda. Dari hasil pengumpulan sampel data dari beberapa sumber pustaka, dan atau responden masarakat (tokoh) di Kabupatén Kuningan ditemukan ada cerita rakyat masyarakat Sunda dari berbagai genre, yang terdiri 7 (tujuh) cerita rakyat has Masyarakat Kabupaten Kuningan dan 12 (dua belas) cerita rakyat masyarakat Sunda 
52 Jaelani Cerita Rakyat di Kabupaten Kuningan sebagai Rujukan Bahan Ajar Mata Pelajaran Bahasa Sunda; Kajian Foklor

secara umum yang tersebar di Kabupaten Kuningan. judul-judul kumpulan cerita rakyat tersebut di rinci sebagai berikut;

\section{1) Kumpulan Cerita Rakyat Has Masyarakat Kabupaten Kuningan:}

(1) Asal Mula Ngaran Kampung Olécéd (Babad/ asal mula ngaran tempat),

(2) Asal Mula Ngaran Jalaksana (Babad/ asal mula ngaran tempat),

(3) Embah Dako (Farabel),

(4) Syéh Abdul Kodir Jaélani (Farabel),

(5) Sasakala Cigugur (Sasakala/ Legenda),

(6) Sasakala Batu nu Bisa Ceurik (Sasakala/ Legenda), dan

(7) Hawangan Surakatiga (Sasakala/ Legenda)

\section{2) Kumpulan Cerita Rakyat Masyarakat Sunda yang Tersebar di Kabupaten Kuningan}

\section{:}

(8) Sakadang Kuya jeung Sakadang Maung Silih Duruk (Fabel/ Dongéng Sasatoan),

(9) Sakadang Kuya jeung Monyet Ngala Nangka (Fabel/ Dongéng Sasatoan),

(10) Si Kabayan di Cukur (farabel),

(11) Tukang Kai (farabel),

(12) Ciung Wanara (Babad),

(13) Nyi Antéh (Mite/ Mitos),

(14) Sangkuriang (Sasakala/ Legenda),

(15) Sireum jeung Gajah (Fabel/ Dongéng Sasatoan),

(16) Bulu Lutung Hideung (Fabel/ Dongéng Sasatoan),

(17) Maung Panjalu (Mite/ Mitos),

(18) Oray Cai teu Peurahan (Sasakala/ Legenda),dan

(19) Hayam Pelung (Sasakalal Legenda).

\section{Nilai Moralitas Dalam Kumpulan Cerita Rakyat Masyarakat Kabupaten Kuningan}

Setiap manusia Sunda sempurna wajib menjalankan beberapa kebiasaan moralitas, diantaranya; 1) Pengkuh agamana (Moral manusia kepada Tuhan), 2) Luhung élmuna (Moral manusia kepada alam dan waktu), 3) Jembar budayana (Moral manusia terhadap dirinya dan juga sesama manusia) dan,4) Rancagé gawéna (Moral manusia menuju kepuasan lahir dan batin). Dari hasil analisis nilai moralitas, dari 19 kumpulan cerita rakyat masyarakat Kabupaten Kuningan, tercatat hanya 17 keseluruhan cerita mengandung nilai moralitas. Dan dilihat dari isinya, ditemukan ada 6 (enam) nilai moralitas, yaitu; (1) moral manusia kepada Tuhan, (2) moral manusia trhadap dirinya, (3) moral manusia ka pada sesame manusia, (4) moral manusa terhadap waktu, (5) moral manusa terhadap alam, dan (6) moral manusia campuran. Berikut adalah tabel yang berisi klasisfikasi analisis nilai moralitas yang terhimpun di kumpulan cerita rakyat Kabupaten Kuningan: 


\section{Analisis Nilai Moralitas dalam (amanat cerita) Kumpulan Cerita Rakyat Masyarakat Kabupaten Kuningan}

\begin{tabular}{|c|c|c|c|c|c|c|}
\hline \multirow{2}{*}{ No } & Judul Cerita Rakyat & \multicolumn{5}{|c|}{ Nilai Moralitas Masayarakat Sunda } \\
\hline & (2) & $\begin{array}{l}\text { MMT } \\
\text { (3) }\end{array}$ & $\begin{array}{c}\text { MMD } \\
\text { (4) }\end{array}$ & $\begin{array}{l}\text { MMM } \\
\text { (5) }\end{array}$ & $\begin{array}{l}\text { MMW } \\
\text { (6) }\end{array}$ & $\begin{array}{c}\text { MMA } \\
(7)\end{array}$ \\
\hline 1 & $\begin{array}{l}\text { Asal Mula Ngaran Kampung } \\
\text { Olécéd (Babad) }\end{array}$ & - & - & & & - \\
\hline 2 & $\begin{array}{l}\text { Asal Mula Ngaran Jalaksana } \\
\text { (Babad/ asal mula ngaran } \\
\text { tempat), }\end{array}$ & - & - & - & - & $\checkmark$ \\
\hline 3 & Embah Dako (Farabel), & - & - & $\checkmark$ & & - \\
\hline 4 & Syéh Abdul Kodir Jaélani & $\checkmark$ & - & $\checkmark$ & - & \\
\hline 5 & $\begin{array}{l}\text { Sasakala Cigugur (Sasakalal } \\
\text { Legenda), dan }\end{array}$ & - & - & $\checkmark$ & - & $\checkmark$ \\
\hline 6 & $\begin{array}{l}\text { Sasakala Batu nu Bisa } \text { Ceurik } \\
\text { (Sasakala/ Legenda) }\end{array}$ & & & $\checkmark$ & & \\
\hline 7 & $\begin{array}{lll}\text { Hawangan } & \text { Surakatiga } & \text { (Sasakalal } \\
\text { Legenda) } & & \end{array}$ & & & $\checkmark$ & & $\checkmark$ \\
\hline 8 & $\begin{array}{l}\text { Sakadang Kuya jeung Sakadang } \\
\text { Maung Silih Duruk (Fabel/ } \\
\text { Dongéng Sasatoan) }\end{array}$ & & & & $\checkmark$ & $\checkmark$ \\
\hline 9 & $\begin{array}{l}\text { Sakadang Kuya jeung Monyet } \\
\text { Ngala Nangka (Fabel/ Dongéng } \\
\text { Sasatoan) }\end{array}$ & & & $\checkmark$ & & \\
\hline 10 & Si Kabayan di Cukur (farabel) & & & & $\checkmark$ & \\
\hline 11 & Tukang Kai (farabel) & $\checkmark$ & & & & \\
\hline 12 & Ciung Wanara (Babad) & & $\checkmark$ & $\checkmark$ & & \\
\hline 13 & Nyi Antéh (Mite/ Mitos) & $\checkmark$ & & $\checkmark$ & & \\
\hline 14 & Sngkuriang(Sasakala/ Legenda) & & $\checkmark$ & & $\checkmark$ & \\
\hline 15 & $\begin{array}{l}\text { Sireum jeung Gajah (Fabel/ } \\
\text { Dongéng Sasatoan) }\end{array}$ & & & $\checkmark$ & & \\
\hline 16 & $\begin{array}{l}\text { Bulu Lutung Hideung (Fabel/ } \\
\text { Dongéng Sasatoan) }\end{array}$ & - & - & - & - & - \\
\hline 17 & Maung Panjalu (Mite/ Mitos) & & & $\checkmark$ & & \\
\hline 18 & $\begin{array}{l}\text { Oray Cai teu Peurahan (Sasakalal } \\
\text { Legenda) }\end{array}$ & & & $\checkmark$ & & \\
\hline 19 & Hayam Pelung (Sasakalal Legenda) & & & & & $\checkmark$ \\
\hline
\end{tabular}


54 Jaelani Cerita Rakyat di Kabupaten Kuningan sebagai Rujukan Bahan Ajar Mata Pelajaran Bahasa Sunda; Kajian Foklor

*Keterangan :

(1) MMD, Moral Manusia Terhadap Dirinya,

(2) MMT, Moral Manusia Terhadap (Tuhan),

(3) MMS, Moral Manusia Terhadap Sesama,

(4) MMA, Moral Manusa Terhadap Alam,

(5) MMW, Moral Manusa Terhadap Waktu.

Dari hasil klasifikasi tabel diatas, Masyarakat Sunda Kabupaten Kuningan Provinsi Jawa Barat, memiliki karakter yang masih kental dalam menyebarkan tradisi lisan salahsatunya cerita rakyat (folktale). Dari hasil analisis sample data, baik bersumber pustaka maupun responden tokoh ditemukan 19 (Sembilan belas) kumpulan cerita rakyat. Genre yang ada dari ke-sembilanbelas kumpulan cerita rakyat tersebut meliputi: 1) enam genre sasakala (legenda), 2) empat genre dongéng sasatoan (fabel), 3) dua bergenre mite (cerita mitos), 4) tiga genre kahirupan manusa (farabel), dan 5) empat bergenre babad (cerita asal muasal kejadian tempat). Dan dari 19 (sembilan belas) data cerita rakyat, 7 (tujuh) diantaranya cerita rakyat has yang tersebar turun temurun di masyarakat Sunda Kabupaten Kuningan, sedangkan 12 (dua belas) kumpulan cerita rakyat lainny merupakan cerita rakyat masyarakat Sunda di Tatar Jawa Barat dan Banten yang tersebar pula di masyarakat Kuningan. Dari hasil analisis moralitas sampel 19 (sembilan belas) kumpulan cerita rakyat yang didapatkan di masyarakat Sunda Kabupaten Kuningan, sementara hanya 17 yang mengarah kepada nilai moralitas kehidupan, sementara 2 (dua) kumpulan cerita rakyat belum mengarah pada nilai moralitas. Seperti penjabaran nilai moralitas yang ditemukan yaitu: (1) moral manusia kepada tuhan (MMT), yang berjumlah 3 (tiga) cerita rakyat (15\%), berjudul "Nyi Anteh, Tukang Kai, jeung Syekh Abdul Qodir Jaélani”; (2) moral manusia terhadap dirinya (MMD), berjumlah 2 cerita ( 10,5 \%), berjudul "Ciung Wanara dan Sangkuriang”; (3) moral manusia terhadap manusia (MMM), berjumlah 11 cerita rakyat ( 57,8 \%), berjudul "Embah Dako, Syeh Abdul Qodir Jaélani, Sasakala Cigugur, Sasakala Batu Ceurik, Hawangan Surakatiga, Sakdang Kuya jeung Monyet Ngalanangka, Oray cai Teu Peurahan, Sireum jeung Gajah, Nyi antéh, Ciung Wanara, dan Maung Panjalu”; dan (4) Moral manusia terhadap alam (MMA), berjumlah 5 (lima) kumpulan cerita rakyat (26\%), berjudul "Hayam Pelung, Sasakala Cigugur, Hawangan Surakatiga, Sasakala Jalaksana, Sakadang Kuja Jeung Maung Silih Duruk ”. sedangkan (5) Moral manusia terhadap waktu (MMW) ada 3 (tiga) cerit rakyatr (15\%), berjudul "Sangkuriang, Si Kabayan di Cukur, dan Sakadang Kuya jeung Maung silih Duruk" setelah diringkas nilai moralitas yang terdapat dari sampel data 19 kumpulan cerita rakyat Masayarakat Sunda Kabupaten Kuningan dominan mengarah ke nilai Moralitas Manusia terhadap sesame Manusia (MMM) sebanyak 11 cerita rakyat, dan tidak sedikit pula 
setiap setip judul cerita rakyat memiliki fungsi ganda nilai moralitas seperti ditayangkan di tabel 4.1 diatas.

\author{
Contoh Rujukan Bahan Ajar dari Kumpulan Cerita Rakyat Masyarakat Kabupaten \\ Kuningan \\ MATERI AJAR \\ (Dimensi Kurikulum 2013)

$\begin{array}{ll}\text { Tema } & \text { : Disesuaikan } \\ \text { Subtema } & \text { :Disesuaikan } \\ \text { Pembelajaran } & \text { : Disesuaikan } \\ \text { Kelas/ Semester } & \text { :Disesuaikan }\end{array}$

Materi A. Bahasa Sunda

\title{
"Sireum jeung Gajah"
}

Jaman baheula keur ngarak rajana, ngaliwat kana alur jajalaneun gajah. Keur ramé ngarak, jol datang gajah. Sireum nu sakitu keur nakleukna téh, teu antaparah deui, leyé-leyé baé ditincakan, bongan ceunah maké ngaliud di jajalaneun. Atuh lain ratus deui, tapi aya rébuna sireum anu paéh téh. Barang raja sireum ningal baladna réa nu paéh, kacida ambekna, tuluy susumbar, "Éh Sakadang Gajah, sato nu telenges, nu teu boga rasrasan ka papada makhluk, rasakeun pamales ti kami. Ulah adigung asa aing. Engké di Jumaah Kaliwon, urang perang tanding jeung kami!"Walon gajah bari seuri, "Rék ngajago Sakadang Sireum téh? Lamun enyaan, heug ku kami didagoan! Dimana hayang perang téh?"Tuh di ditu, di handapeun tangkal waru nu itu, nu condong ka jalan!" Gancang, gajah nuluykeun deui lampahna. Ari raja sireum teu talangké deui, tuluy baé nabeuh tangara, ngumpulkeun kabéh baladna. Teu sabaraha lila, balad sireum téh geus nakleuk di tegalan.Ceuk Raja Sireum, "éhh balad kami kabéh! Di Jumaah Kaliwon kaula rék perang tanding jeung Sakadang Gajah, tuh handapeun tangkal waru nu itu! Ku sabab éta, kaula ménta ka aranjeun sakabéh ulah cicingeun, kudu pada digarawé. Saréréa kudu nyieun lombang sing gedé pikeun piruang. Nya palebah warna nu itu kudu nyieun piruang téh. Prak geura digarawé ti ayeuna. Tapi kadé jukutna mah ulah ruksak, kudu angger baé kawas ayeuna. Dikorowot ti jero baé, taneuhna engké sésakeun, tuh kira sakandeul papan beunang Sakadang Manusa, ka luhurna mah."Balad sireum saur manuk, kabéh pada jangji rék pada suhud digarawé, sarta pada sanggup anggeus dina waktu tujuh poé. Saomong balad sireum teu nyalahan, dina waktu tujuh poé piruang téh geus bérés. Tiluhurna teu katara, teu jiga piruang meueus-meueus acan, kawantu buatan para ahli nerus bumi.Barang nepi kana waktuna, kana poé Jumaah Kaliwon téa, subuh kénéh Raja Sireum geus ngabedega sisi piruang beulah kulon, nyahareup ngétan. Saksi-saksi geus karumpul, nyaéta: Sakadang Peucang jeung Sakadang Monyét. Wanci haneut moyan, jol Sakadang Gajah ti beulah wétan maju ka kulon, nyampeurkeun Raja Sireum.Jauh kénéh ogé Raja Sireum geus celuk-celuk nangtang ka Sakadang Gajah, "gancang kadieu Sakadang Gajah, ieu sihung kami geus seukeut meunang ngasah tujuh poé tujuh peuting, geus sadia bakal maéhan sampéan. Lamun enya sampvan sakti, gancang geura rontok kami!"Barang gajah ngadengé panantang Raja Sireum kitu, jol suruwuk baé narajang. Tapi cilaka, teu kungsi nepi, da awakna kaburu tigebrus mantén kana piruang, sukuna tipitek. Sakadang Gajah adug-adugan méakeun tanaga hayang kaluar tina piruang, tapi weléh teu bisa. Tungtungna béak tanaga hayang kaluar tina piruang, tapi weléh teu bisa. Tungtungna béak tanaga ngajoprak teu bisa walakaya. Ceuk raja Sireum ka balad-baladna, "pék ayeuna geura hanca ku aranjeun éta sato telenges téh!"Balad sireum nu réana mangyuta-yuta, bareng narajang, napuk kana sakujur awak Sakadang Gajah. Gajah ripuh dicocoan ku sireum. "ampuuuun. . ampuuun!" Sakadang Gajah tulung-tulungan ménta ampun. Manéhna taluk tarima éléh, jeung jangji moal deuo-deui ngaganggu ka bangsa sireum. Tidinya riwayatna, aya paribasa "Sireum ogé ditincak-tincak teuing mah sok ngalawan". Atuh lamun aya nu suten, jempol anu jadi perlambang gajah, éléh ku cinggir anu jadi perlambang sireum.

\section{SIMPULAN DAN SARAN}


56 Jaelani Cerita Rakyat di Kabupaten Kuningan sebagai Rujukan Bahan Ajar Mata Pelajaran Bahasa Sunda; Kajian Foklor

Dari penjelasan diatas mengenai analisis klasifikasi nilai moralitas dalam cerita rakyat atau folktale yang tersebar, walaupun cerita rakyat bersifat non logis atau tidak masuk akal, jika di kaji secara mendalam setiap cerita rakyat memiliki fungsi pendidikan dan nilai moralitas yang bisa menambah khasanah etnopedagogik sebagai rujukan tambahan bahan materi ajar.

\section{REFERENCES}

Bachman, Edmund. (2005). Metode Belajar Berpikir Kritis dan Inovatif. Jakarta: PT Prestasi Pustakaraya

Nurhadi. (2008). Membaca Cepat dan Efektif. Bandung: Sinar Baru Algensindo.

Resnick B. Lauren. (1987). Educational and Learning To Think. National Academy Press. Washingto, D.C.

Silberman, Melvin L. (2006). Active Learning 101 Cara Belajar Siswa Aktif. Bandung: Nusamedia.

Soedarso. (2001). Sistem Membaca Cepat dan Efektif. Jakarta : Gramedia

Stone, Randi. (2009). Cara-cara Terbaik Mengajarkan Matematika. Jakarta : Indeks

Sudjianto. (1995). Kemampuan Berbahasa Indonesia. Jakarta : Depdikbud.

Sugiyono. (2005). Statistika untuk Penelitian. Bandung: ALFABETA.

Suhendar, M.E. \& Supinah, P. (1992). Pengajaran dan Ujian Keterampilan Membaca dan Keterampilan Menulis MKDU Bahasa Indonesia ). Jakarta : Depdikbud

Tampibolon, D.P. (1990). Kemampuan Membaca, Teknik Membaca Efektif dan Efisien. Bandung : angkasa.

Tarigan, H.G. (1990). Membaca dalam kehidupan. Bandung : Angkasa..

Trianto. (2007). Model-model Pembelajaran Inovatif Berorientasi Konstruktivistik. Jakarta Prestasi Pustaka

Wiryodijoyo, S. (1989). Membaca, Strategi, Pengantar dan Tekniknya. Jakarta : Depdikbud. 